\title{
Consumer-Producer Interaction: A Strategic Analysis of the Market for
}

\section{Customized Products}

Niladri B.Syam ${ }^{1}$

Benedict G.C. Dellaert ${ }^{2}$

Jan 2001

${ }^{1}$ College of Business Administration, University of Houston, 4800 Calhoun Road, Houston, TX 77204

Email:nbsyam@uh.edu, Phone 713743 4568, Fax 7137434572

${ }^{2}$ Department of Marketing, Faculty of Economics and Business Administration, Tilburg University, PO Box 90153, 5000 LE Tilburg, The Netherlands Email: dellaert@kub.nl, Phone: +31 13466 8224, Fax:+31 134662875

Acknowledgements: The second author's research on this project was partly funded

by a grant from the Dutch Science Foundation (NWO-ESR). Paul Driessen's and

Ram Rao's comments on an earlier version of this paper are much appreciated.

Niladri B. Syam is an Assistant Professor of Marketing, College of Business Administration at The University of Houston. He received his M.S in Operations Research and Ph.D in Management Science from The University of Texas at Dallas. Previously, he taught at Tilburg University, The Netherlands. He is interested in modeling competition with an emphasis on strategic issues. Substantive areas of interest include retail competition, joint promotions by two or more firms and 
processes of consumer-producer interaction. His research has previously appeared in Marketing Science.

Benedict Dellaert is an assistant professor of Marketing at the Department of Marketing, faculty of Economics and Business Administration, Tilburg University, The Netherlands. His Ph.D. is from Eindhoven University of Technology. Benedict's research interests are in choice modeling, interactive marketing and retailing. His publications have appeared in journals such as the Journal of Marketing Research, the International Journal of Research in Marketing, and Marketing Letters. When he is not working on marketing research Benedict can often be found pursuing his interests in tourism, both as a researcher and a participant. His work in this area has appeared in journals such as Leisure Sciences, Annals of Tourism Research and Tourism Management. 


\title{
Consumer-Producer Interaction: A Strategic Analysis of the Market for
}

\author{
Customized Products
}

\begin{abstract}
This paper analyses the process in which producers interact with consumers to elicit information that enables them to better serve their consumers. This happens in many situations but is arguably most prominent in mass-customization, an area that has recently gained a lot of popularity among manufacturers (Business Week, March 20, 2000). In terms of communications, such interaction entails a shift from the one-way communication (usually from seller to buyer) of traditional markets, to a two-way communication. Specifically, potential producers need to elicit preference (and other) information from consumers. They then have to provide a product that correctly incorporates such information. This brings up many strategic issues.

In this research we are interested in answering the following questions: (1) What is the 'economic value' of consumers' information? (2) Are there any strategic implications for producers, if they depend on consumer input and have to pay for consumers' information? (3) In what way does pricing for customized products differ from pricing for similar standardized products? (4) Is the strategic relationship between consumers and producers different in the market for customized goods as compared to more traditional markets? The main contribution of this paper is to bring into focus the issues surrounding mass-customization via an analysis of consumerproducer interaction, which is the facilitating process. This paper is the first attempt in marketing to analytically model this emerging area and should be of interest to academics. Practitioners should be interested in this paper's marketing and strategic perspective on mass-customization. While the trade press has approached masscustomization from a manufacturing/production cost angle, its marketing implications have largely been left open (Wind and Rangaswamy, 2000).

We build a game-theoretic model, which analyses the interaction between consumers and producers in an agency-theoretic framework. In our model some firms in a market have the ability to customize, thereby adding quality to their product, if they have interacted with customers. Interaction with firms can be costly for consumers. The model has firms that can/cannot customize successfully and consumers who have a high or low value valuation for customized products. The game has two stages. In the first stage, producers solicit consumers' suggestions/preferences and consumers decide whether to interact with the firm and provide information. (Stage 1: 'Information market'). The main concern for firms at this stage is to screen consumers so as to have only those consumers with a high value for customization, interact with it. In the second stage, firms try to provide a product, which correctly incorporates consumers' input and set prices for such customized products (Stage 2: 'Product market'). The main question for consumers at this stage is whether the producer has been able to successfully incorporate their input given in the first stage. We begin with the monopoly case to provide a benchmark and to isolate the strategic issues in consumer-producer interaction. Later we incorporate competition between firms. In the latter case, both the information market (where firms compete for consumers' information) and the product market (where firms compete to sell the final product) have interesting interactions.
\end{abstract}


We find that, in equilibrium, firms will have to pay consumers for their information in the first stage. Intuitively, consumers provide costly input, but any commitment by the firm to provide surplus through a lower price of the product in the second stage, lacks commitment. In other words, having sunk in the first stage cost of interacting, rational consumers would expect the firm to set second stage prices so as to extract all their surplus from consuming the product. Consumers would then be left with a negative utility to the extent of their cost of interaction. Therefore, in a noncontractual setting, the firm will have to compensate consumers upfront for their input. Moreover, the producer's payment can act as a signal of high quality for the skillful customizer who tries to separate from a 'ghost firm', which cannot customize well. The firm that cannot customize successfully will also have to pay consumers if it chooses to interact with them. But, having done that, it cannot translate this information into additional sales. Thus it will choose not to interact in the first stage. Under monopoly, the price of customized products is the same as that of noncustomized products, contrary to common wisdom as reflected in the trade press (Anderson, 1997). The successful customizer can better serve consumers and better fulfill their customization needs because of its knowledge of their preferences. But it is the consumers themselves who are the 'producers' of that information. Since consumers create that part of the value addition in a product, the firm cannot charge a higher price for it. Thus, our analyses could explain why some manufacturers find that they cannot charge a premium for customized products (Wind and Rangaswamy, 2000). We find that equilibrium prices of customized products are at the high end of the price range for similar non-customized products, consistent with casual observation.

Under duopoly, when firms compete for consumers' information, the prices of customized products are in fact less than the price of non-customized products. This counter-intuitive result occurs because firms try to avoid being heldup by consumers who may withhold purchase, after first getting the firm to produce a very individually tailored product which the firm might not be able to sell to other consumers. Since, first stage competition for information gives consumers a high price for their information, it increases their incentive to holdup the firm. The firm, therefore, has to charge a lower price to induce consumers to purchase the product in the second stage.

Finally, we show that, in the market for customized goods (stage 2), consumers can be better off with less competition between firms. Intuitively, the consumer's compensation for providing information is directly related to the extra profit that the firm can make from that information. When firms compete in the product market in the second stage, they earn less equilibrium profits. Thus, they compensate consumers less for their information in the first stage, and this may yield consumers less overall utility. Thus, in the market for customized goods, consumers may be better off by making a firm the monopoly supplier of their customization needs. This finding could be of interest to manufacturers who increasingly attempt to build deep, long lasting ties with consumers. Often such ties are perceived as conflicting with the consumers' desire to retain the flexibility to compare and opt for the offerings of different producers. Our results suggest that such misalignment of interests need not exist, at least in the market for customized goods.

Key Words: Customization, Consumers' Information, Information Market, Product Market, Agency Theory, Horizontal Features, Vertical Features 


\section{Introduction}

Increasingly, academics and practitioners view marketing as an interactive process where relationships -often between buyer and seller- become an important cornerstone. Concepts such as, Relationship marketing, One-to-one marketing and Interactive marketing (e.g., Deighton and Glazer 1998, Fournier et al. 1998, Gilmore and Pine 2000 and Peppers, Rogers and Dorf 1999) all center around this view. Arguably, they are most appropriate in processes where sellers and buyers rely on each other to co-create better value in the exchange process in which they participate. In terms of communication between buyer and seller, this type of approach to marketing can be seen as a shift away from one- way communication (usually from the seller to the buyer) towards a two-way communication process. This trend has increased and is expected to accelerate with technological advances. Technology, especially the combination of flexible manufacturing and internet-based information and communication technology has altered the traditional product development process and production process by being able to incorporate consumer tastes or preferences throughout the product development period.

This is most prominent in the emerging strategy of mass-customization, which has unleashed a wave of changes in several industries. Jeffrey D. Roth, the chairman and founder of a new website devoted to customized goods that has 100 product categories and expects to have 2000 within a year, says that most major manufacturers have some kind of customized product under way at the moment, if they haven't launched one already (Business Week, March 20, 2000).

In addition to requiring an improved consumer-to-supplier information flow, a customization strategy also will have an impact on more traditional supplier-toconsumer marketing communication. Firms are realizing that, more and more 
consumers have information about the product solutions that they require, and that firms will have to devise means to elicit such information from them. Firms then have to provide products that satisfactorily incorporate the consumer suggestions thus elicited. However, despite its growing popularity in marketing practice and the attention it has received in the trade press, co-opting consumer competence has hardly been investigated in the academic literature.

This paper seeks to fill a gap in the literature by analytically modeling the process of consumer-producer interaction and studying the strategic issues in such processes. Our contribution is in three broad areas. First, we address the issue of ownership and the 'economic value' of consumers' information. This has to do with whether firms should compensate consumers for their information and the determination of the optimal price of such information. Secondly, we address the issue of pricing of products co-created with consumer input. We find that firm's pricing strategies when consumers are co-creators may be radically different from their strategies in more traditional markets. Thirdly, we address the strategic relationship between producers and consumers in mass-customization. Surprisingly we find that, in the market for customized goods, consumers can actually be better off with less competition between firms. Thus, our paper contributes to the ongoing debate about customization and tackles some issues, which arise in such processes through an analytical modeling of this phenomenon. Moreover, it addresses the important question of the impact of customization on marketing, which as Wind and Rangaswamy (2000) have pointed out is a topic that is still under-researched, in contrast to the impact of customization on manufacturing.

Previously, competition in the market for information has been studied by Sarvary and Parker (1997) and Iyer and Soberman (2000). They modeled situations in 
which firms compete to sell information to a population of business customers who are heterogeneous in their willingness to pay for the quality of information. Sarvary and Parker's main goal was to demonstrate that information markets face unique competitive structures, while Iyer and Soberman investigated optimal selling policies for a vendor of (consumer population level) product modification information. Our aim is to study the process in which consumers provide information to potential producers who then supply a product incorporating this input, through an agencytheoretic analysis of this interaction. In doing so, we address the issues of consumers' incentives to provide private information and the optimal price that firms would pay for such information. We also model the mechanism by which price-setting of consumers' information is a result of firms' competition for that information. This reflects the notion that, "In many respects, we are moving...into a new era in which the defining battle is that for customer profiles" (Hagel and Singer, 1999a). In addition, we throw light on the interaction between the information market and product market both of which arise in consumer-producer interaction: the consumer supplies information and the producer supplies the product.

\subsection{Consumer Input}

Consumer's input into producing the final product that is consumed by them can take many forms. From an information market perspective, it is important to make the distinction between different types of consumer input. First, consumers can provide information that improves the quality of the final product for all consumers. This could happen, for example, with the input of beta testers for software products. It could also be the case with lead-users whose current strong needs will become general in a marketplace months or years into the future. In terms of the economics literature on product differentiation, such input creates differentiation in the Kaldorian tradition 
of vertical features, we therefore refer this type of quality improvement as 'quality in the Kaldorian sense'. Secondly, consumers can provide input that improves the product only for themselves but does not improve the quality of the product for others. This could happen, for example, when consumers provide information about their own unique preferences for different attributes. In this paper, we address only the second type of consumer input, which creates product differentiation in the Chamberlinian tradition of horizontal features or highly idiosyncratic quality attributes ('quality in the Chamberlinian sense'). The second type of quality improvement process generates the most interesting strategic issues in the consumerproducer interaction. Furthermore, the process is most likely to happen when a firm co-creates personalized experiences with its consumers as opposed to using consumer input for product development and improvements from an objective standpoint.

In this context, one of the few studies that have addressed customization is Huffman and Kahn (1998) who have approached mass-customization from the consumers' viewpoint. They have shown that the way information is presented and the type of consumer input to the information gathering process influence consumer satisfaction. In particular, they show that consumers are more satisfied when they are asked to explicitly indicate their preferences for attributes, as compared to more effortful or less effortful tasks. In our study however we focus on strategic issues in consumer-producer interaction in customization and assume that consumer contributions and product utility are independent of the specific type of customization process. 


\subsection{Customization}

Prahalad and Ramaswamy (2000) distinguish between customization and personalization. According to their definition, customization assumes that the manufacturer will pre-design a product so as to suit the needs of different consumers. This could happen when the manufacturer forces the consumer to choose from a predetermined menu of features. Personalization, on the other hand, is about the consumer becoming a co-creator of the content of their experiences. Some of the issues surrounding consumer-producer interaction disappear when customization is defined in the sense of Prahalad and Ramaswamy. For example, if a consumer only has to choose from a menu of features, then many concerns about quality of customization are alleviated. This is the case because, customization then is merely putting together features whose qualities can already be known to the consumer. However, if there is processing or value addition to be done by the manufacturer after the consumer's input, and incorporating that input, then there are serious questions about the quality of customization. This is so because the final product comes into existence after the consumer has already provided input which, in some cases, could be quite costly for the consumer. The consumer would of course want to ensure that the final product successfully incorporates his or her input. There is then a moral hazard problem, as the firm knows its ability to customize but the consumer does not. Wind and Rangaswamy (2000) point out that one of the key challenges of customization is that it creates higher consumer expectations as compared to more traditional processes. They note that, "If it [the producer] fails to meet these expectations, they [the consumers] will likely be far more disappointed and dissatisfied than if they had bought a standardized product". The moral hazard problem, or alternatively, the firm's ability to customize, is then a serious issue. 
Furthermore, if the firm tailors a product to only one specific consumer's need, then the firm is also subject to holdup as that consumer may not purchase the product after his or her input has been incorporated into it. The firm is then left with a product, which it might not be able to sell to another consumer. This risk is, of course, most critical when the firm produces a product in response to consumer input. Interestingly, Anderson (1997) a management consultant specializing in mass customization, writing in one of the more authoritative books on implementing mass customization in manufacturing argues that true customization involves the incorporation of consumers' desires in the product. That is, the product comes into existence after the consumer's input. Giving more consumers more choices in the hope that they can find something close to what they need is variety, not customization. Anderson goes on to say, "Fundamentally, customers do not want choice; they just want exactly what they want". Addressing mass customizers (or customizers in the Prahalad and Ramaswamy sense) he says

It is customization only if it is produced in response to a particular customer's desires...your task is to figure out (often through collaboration) exactly what they need and then produce it...( Anderson, 1997)

Thus, the definition of customization is still somewhat different between different authors in the field. In this paper we focus on personalization in the Prahalad and Ramaswamy sense in which firms have to deliver tailored products co-created by consumers. We choose to focus on personalization as it opens up many interesting strategic possibilities like the moral hazard problem and the holdup problem mentioned in the previous paragraph. In particular we focus on consumer-producer interaction as the facilitating process in personalization and the strategic issues involved in it. Potential consumers have to share their knowledge about their needs 
and possible product solutions with producers. The producer then attempts to deliver a product to the consumer incorporating the consumer's suggestions. However, as the trade press and most academic literature do not make a clear distinction between customization and personalization we use the more common term, customization, in what follows.

In the next section we describe in detail our research problems and provide intuitions for our results. The model is developed formally in section 3. Before concluding, we discuss some salient features of our model in section 4.

\section{Research Problems}

Interacting with potential producers is not without behavioral or financial cost for consumers. As a recent article in Business Week pointed out:

One problem with customization is that it requires customers to do a lot of the initial legwork. That means filling out forms, picking choices, standing in scanning booths, and otherwise going through the hassle of helping manufacturers take the guesswork out of serving their needs. (Business Week, March 20, 2000)

The 'legwork' mentioned in the quote above clearly create resistance, on the part of consumers, to interacting with suppliers. Some practitioners have gone so far as to say that producers should pay consumers for their information in order to overcome their resistance (Hagel and Singer, 1999b). In fact, strategic behavior on the part of rational consumers, who realize that they have something that firms want, may force the issue. This viewpoint is reflected in the following quotes 
Consumers can extract value [from producers] in ways that were unimaginable even three years ago... Armed with knowledge, customers are much more willing to negotiate terms and prices with companies. (Prahalad and Ramaswamy, Harvard Business Review, Jan-Feb 2000)

In large part, consumers will make the decision to sell or not to sell [information] by evaluating what companies offer in return...marketers would pay handsomely for such information. (Hagel and Singer McKinsey Quarterly, 1999 Number 1)

Consumers increasingly recognize that they are selling their privacy on the cheap to companies...Consumers, after all, are rational. Most have shown that they will release personal information if they can profit by doing so. (Hagel and Singer, McKinsey Quarterly, 1999 Number 1)

The question then is: Can such compensation for consumer information be part of an equilibrium of a game in which strategic consumers interact with firms to fulfil their customization requirements? More interestingly, is such compensation a necessary evil for the firms? In other words, are there any positive strategic implications for firms if they pay for consumers' information? By explicitly bringing in the ownership and 'economic value' of consumer information into our model, we are able to investigate the strategic implications of such information both for the firms as well as for the consumers themselves. We find that, in equilibrium, firms will pay for consumer information, given a consumer's positive cost of providing that information. Having shared their preference information with a firm, strategic consumers realize that the firm will use it to extract full consumer surplus for the product via perfect price discrimination. This will yield the consumer a negative total surplus to the extent of their cost of providing information, unless they are compensated for it. More importantly, we show that such compensation can play the role of a signaling device for the firm if consumers are uncertain about product quality (or equivalently, the 
firm's ability to customize). Another way to look at this is in terms of information asymmetries. Traditional markets are characterized by a two-sided asymmetry. Buyers have information about their preferences while sellers have information about their ability to supply quality. Asymmetry in favor of buyers (about their preferences) is a counterbalance to the asymmetry in favor of the sellers about product quality. In consumer-producer interaction, however, consumers first provide information about their preferences to the seller thus creating a higher-level asymmetry in favor of the seller. Therefore, such compensation, as exists in our equilibrium, can reduce the asymmetry against buyers by acting as a signaling device for the seller's quality. Thus we see that it might actually be in the interest of the firm to pay consumers for their information.

Another issue is the price setting for products, which have resulted from such consumer-producer interaction. The question of interest here is whether, and under what conditions firms could charge higher prices for supplying customized products. The trade press is unclear regarding this issue. Most authors have approached the mass-customization debate from a production-cost oriented viewpoint and seem to argue that prices of customized products are expected to be higher than noncustomized products reflecting the higher production costs, but that these prices are falling as technology is driving production costs down. Witness the following quotes Now the cost [of getting information to deliver customized products] has fallen sharply. And masscustomization allows companies to use such information to introduce individually tailored products at affordable prices. (The Economist, April 2000)

Customers can communicate directly with manufacturers via the internet, and their instructions can be absorbed into the production at little-if any-extra cost. (Business Week. March 2000) 
The development of Just-in-Time delivery, lean production techniques, early manufacturing involvement, time-based competition, cross-functional teams, and a host of other techniques has honed process flexibility and responsiveness- and therefore optimized the ability to increase variety without significant jump in costs. (Chief Executive, March 1993)

By approaching customization from a production-cost standpoint these authors have left open the strategic issues involved in the pricing of personalized products. But, from a marketing point of view, pricing which is a result of strategic forces in the market is more interesting than the production cost approach. We therefore ask if strategically behaving consumers would pay more for customized products in equilibrium. The trade press seems to answer that they would.

Most customers are willing to pay a premium (often 10 to 50 percent) simply because customized products have greater value than standardized ones- they more closely match each individual's needs. (Anderson, 1997)

Moreover, could we ever expect customized products to have lower prices than noncustomized products? If costs were the main driver of prices of customized products, the answer to the above would be negative. However, by explicitly addressing the issue of pricing of such co-created products, we are able to uncover some counterintuitive aspects regarding their equilibrium prices as compared to the prices of noncustomized products. In a monopoly scenario, the equilibrium price of customized products would be exactly the same as that of non-customized products. This holds as long as customization does not involve improvement in the vertical features of the product, but only the incorporation of consumer preferences. However, equilibrium prices of customized products are at the high end of the price range for similar non- 
customized products. This is in consonance with Wind and Rangaswamy's observation that, "Levi's and CD Now found out that they could not charge a large premium for customized products, but they could charge at the top end of the established price range for similar, standardized products" (Wind and Rangaswamy, 2000). However, under duopoly, when there is competition for consumer information, the equilibrium prices of customized products could actually be lower than that of non-customized products. This happens because firms try to avoid consumer holdup. But, by paying a higher price for consumers' information, as a result of competition for it, the firm has actually increased consumers' incentive to do so. Since it cannot sell such a tailor made product to others, it has to charge a lower price in order to induce such over-compensated consumers to buy it.

Finally we address the issue of the relationship between consumers and producers, given the paradigm shift from one-way communication to two-way communication that customization necessarily entails. In traditional markets, there is the widespread belief that the wants and needs of consumers and producers are misaligned. Producers increasingly want to build deep long-lasting ties with consumers. This could have the effect of tying consumers into 'monopolistic relationships'. The growth of various forms of 'loyalty programs', which seek to build consumers' loyalty towards particular producers, is an example of this trend. On the other hand, consumers want to retain the flexibility to compare and opt for the offerings of many different producers. Does the same misalignment of interests hold also in the market for customized goods? Surprisingly we find that in the market for products, under a duopoly situation it may be better for consumers to interact with only one producer (thereby making it a monopoly for supplying their customization needs) rather than with both of them. This counter intuitive outcome is a result of the 
dual role of the 'consumer' in consumer-producer interaction: both as a price maker in the upstream information market and a price taker in the downstream product market. The upstream information market is created because the two firms may bid for consumers' information and the downstream product market is created when they compete to sell to the same group of consumers, after manufacturing a product incorporating this information. The consumer's dual role prevents the higher input cost for the firm, due to competition in the information market, from being reflected in higher output price in the product market, contrary to what we might expect in more traditional markets. This means that the firm makes less profit. Since the price that the firm is willing to pay for consumer's information is directly related to the profits it can make from such information, the firm now pays less for the information. We thus identify a situation in which consumers can actually benefit from restricting competition between firms. We now lay down the details of our formal model.

\section{Model}

\subsection{Monopoly case}

Consider first a market with a single producer and many consumers. The monopoly case serves as a benchmark and allows us to analyze the various issues involved in consumer-producer interaction in a relatively simple setting. We will later introduce competition between producers. There are two types of consumers, the high types and the low types. High type consumers are 'experts' who have a high need for customized products. Low type consumers are 'non-experts' who do not have a high need for customization. The firm or producer can produce an offering to satisfy the preferences of the non-expert consumers without interacting with them to elicit information. But it needs to elicit information about the expert consumer's 
customization needs in order to sell to them. The firm itself can be either of two types. A high type firm is a 'good customizer', which can meet all the customization requirements of consumers. It is common knowledge that the low type firm occurs with probability $\pi^{1}$ and the high type with probability $\pi^{2}$. A low type firm is a bad customizer', which cannot meet consumer's customization requirements. Obviously we expect firms to have various levels of 'customization ability', but we dichotomize this dimension for analytical tractability and because doing so does not compromise our ability to draw meaningful conclusions from our model.

We model consumer-producer interaction as a two-stage game. In the first stage the firm elicits consumer information about their customization requirements. Consumers at this stage decide whether to interact with the firm and provide information. If consumers choose to interact, they have to put in effort $e$ at a cost $c(e)$ and receive compensation $w$. The main concern for the firm at this stage is to screen consumers so as to have only 'experts' interact with them. In the second stage, the producer provides the product/service choosing appropriate prices and qualities and consumers make their purchase decision. In the second stage, the main question for the consumers who have interacted with the producer in the first stage is whether the producer has successfully incorporated their suggestions in the product. Figure 1 summarizes the structure of the game. 


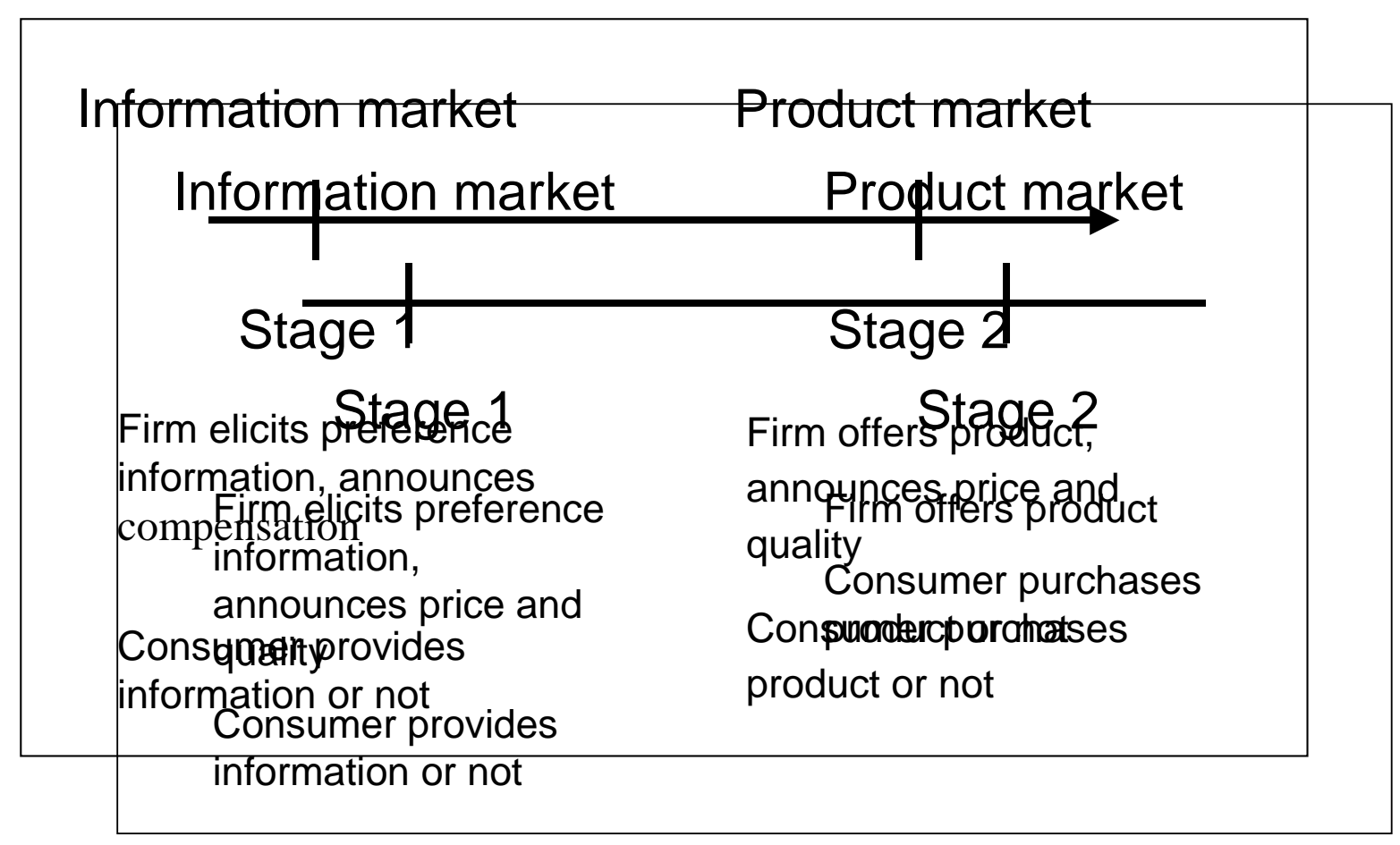

Figure 1 Consumer-producer interaction game

Let $N^{L}$ and $N^{H}$ be the number of 'low type' and 'high type' consumers respectively in the market. Let, $p_{1}, y_{1}$ denote the price and quality (respectively) chosen by the 'low type' firm in the second stage. Similarly, $p_{2}, y_{2}$ are the price and quality chosen by the 'high type' firm in the second stage. Consistent with prior literature, we assume that the cost of providing quality $y$ is convex and given by $c_{1} y^{2}$ for the low type firm and $c_{2} y^{2}$ for the high type firm. Also, the utility from consuming $y$ units of quality is $\theta_{1} y$ for the low type consumer and $\theta_{2} y$ for the high type consumer. We assume that for a product with a given quality level, an expert derives greater benefit from the product than a non-expert (Mussa and Rosen, 1978). The high type firm is able to sell to all consumers - both high and low types. Low type consumers do not have customization requirements and so the high type firm can sell to them. High type consumers have strong customization requirements but the high 
type firm can fulfil those. The low type firm sells only to the low type consumers. In other words, we assume that high type consumers can detect the quality of customization in the product before they purchase it, and they withhold purchase if the firm hasn't been able to customize successfully. As is usual, we will first solve the subgame starting at the second stage. The second stage problem faced by the low type firm is.

\section{$\mathbf{P}_{1}$ :}

$$
\arg \max N^{L}\left(p_{1}-c_{1} y_{1}^{2}\right)
$$

$$
p_{1}, \mathrm{y}_{1}
$$

subject to

$$
\begin{aligned}
& N^{L}\left(p_{1}-c_{1} y_{1}^{2}\right) \geq\left(N^{L}+N^{H}\right)\left(p_{2}-c_{1} y_{2}^{2}\right) \\
& \left(N^{L}+N^{H}\right)\left(p_{2}-c_{2} y_{2}^{2}\right) \geq N^{L}\left(p_{1}-c_{2} y_{1}^{2}\right) \\
& \pi^{1}\left(\theta_{1} y_{1}-p_{1}\right)+\pi^{2}\left(\theta_{1} y_{2}-p_{2}\right) \geq 0 \\
& \pi^{2}\left(\theta_{2} y_{2}-p_{2}\right) \geq w-c(e) \\
& p_{1} \geq 0, \mathrm{y}_{1} \geq 0
\end{aligned}
$$

The first two constraints are the "self selection" or "incentive compatibility" constraints for the low type and the high type firm respectively. The first ensures that the low type firm will choose its own price and quality rather than the high type firm's price and quality. Similarly, the second constraint ensures that the high type chooses its own price and quality. The third and fourth constraints are the "individual rationality" for the low type consumer and the high type consumer respectively. Note that, since the low type consumer does not interact with the firm in the first stage in equilibrium, therefore by not consuming in the second stage s/he gets a reservation utility of zero. But since the high type consumer does interact in the first stage, the reservation utility is $(w-c(e))$. See Maskin and Tirole (1992) for more details about 
the way the problem has been set up. The fourth constraint also prevents the high type consumer from reneging by withholding purchase. It ensures that the consumer is better off by purchasing in the second stage than by not purchasing. Since the high type firm sells also to the low type consumers, in equilibrium it must be that $\theta_{1} y_{2}-p_{2} \geq 0$

Similarly, the second stage problem faced by the high type firm is

$\mathbf{P}_{2}$ :

$\arg \max \left(N^{L}+N^{H}\right)\left(p_{2}-c_{2} y_{2}^{2}\right)$

$p_{2}, \mathrm{y}_{2}$

subject to

$$
\begin{aligned}
& N^{L}\left(p_{1}-c_{1} y_{1}^{2}\right) \geq\left(N^{L}+N^{H}\right)\left(p_{2}-c_{1} y_{2}^{2}\right) \\
& \left(N^{L}+N^{H}\right)\left(p_{2}-c_{2} y_{2}^{2}\right) \geq N^{L}\left(p_{1}-c_{2} y_{1}^{2}\right) \\
& \pi^{1}\left(\theta_{1} y_{1}-p_{1}\right)+\pi^{2}\left(\theta_{1} y_{2}-p_{2}\right) \geq 0 \\
& \pi^{2}\left(\theta_{2} y_{2}-p_{2}\right) \geq w-c(e) \\
& \mathrm{p}_{2} \geq 0, \mathrm{y}_{2} \geq 0
\end{aligned}
$$

The optimal second period prices and qualities are obtained by solving $\mathbf{P}_{\mathbf{1}}$ and $\mathbf{P}_{\mathbf{2}}$ simultaneously and are summarized in proposition 1.

Proposition 1:The optimal prices chosen by the firms in the second stage when they interact with consumers in the first period, are

$$
p_{1}^{*}=\frac{\theta_{1}^{2}}{2 c_{1}}-\frac{c(e)-w}{\pi^{1}}, \text { and } p_{2}^{*}=\frac{\theta_{2}^{2}}{2 c_{2}}+\frac{c(e)-w}{\pi^{2}}
$$

And the optimal qualities are

$$
y_{1}^{*}=\frac{\theta_{1}}{2 c_{1}} \text {, and } y_{2}^{*}=\frac{\theta_{2}}{2 c_{2}} \text {. }
$$


Proof: See appendix A.

We now solve the first stage problem for the firms. Recall that in this stage the firms screen the consumers, attempting to solicit input only from the high type consumers. The profits for the high type and low type firm are given as

$\Pi_{\mathrm{H}}=\left(N^{L}+N^{H}\right)\left(p_{2}-c_{2} y_{2}^{2}\right)-N^{H} w$ and

$\Pi_{\mathrm{L}}=N^{L}\left(p_{1}-c_{1} y_{1}^{2}\right)-N^{H} w$

The first term in either case represents the profit to the firm in the subgame starting at the second stage and the first term is the compensation $w$ that the firm pays the consumers for their input.

Further, the utility to the consumer is

$\Pi_{\text {Consumer }}=w+\underset{-}{p}\left[\pi^{1}\left(\theta_{1} y_{1}-p_{1}\right)+\pi^{2}\left(\theta_{2} y_{2}-p_{2}\right)\right]+\bar{p} \pi^{2}\left(\theta_{2} y_{2}-p_{2}\right)-\frac{c(e)}{k}$

Where $\underline{p}=\frac{N^{L}}{N^{L}+N^{H}}$ and $\bar{p}=\frac{N^{H}}{N^{L}+N^{H}}$

Here $w$ is the compensation the firm pays consumers who have provided input in the first stage, the second and third terms represent the Von-Neumann utility (of consumers who are in the market in the first stage) from consuming in the second stage and the last term is their cost of effort $c(e)$ weighted by their knowledge of the product $k$. Nature chooses the consumer's knowledge of the product $k \in\{\underline{k}, \overline{\mathrm{k}}\}$ with probability $\underline{p}$ and $\bar{p}$ respectively. That is, experts have knowledge $\overline{\mathrm{k}}$ and the probability of being an expert is $\bar{p}$. Similarly for the non-experts.

Substituting the second stage optimal prices and qualities in the above we get $\Pi_{\mathrm{H}}=\left(N^{L}+N^{H}\right)\left[\frac{\theta_{2}^{2}}{4 c_{2}}+\frac{c(e)}{\pi^{2}}\right]-\left[\frac{\left(N^{L}+N^{H}\right)}{\pi^{2}}+N^{H}\right] w$ 
$\Pi_{L}=N^{L}\left[\frac{\theta_{1}^{2}}{4 c_{1}}-\frac{c(e)}{\pi^{1}}\right]+\left[\frac{N^{L}}{\pi^{1}}-N^{H}\right] w$

$\Pi_{\text {Consumer }}=(2-\underline{p}) w-\left(1+\frac{1}{k}-\underline{p}\right) c(e)$

To determine the optimal first period compensation we need to satisfy the participation constraints for the firm. We need to ensure that the high type firm will prefer to interact with consumers in the first stage whereas a low type firm will not. This will establish conditions for a Separating equilibrium in which a high type firm can credibly signal its type by interacting with consumers in the first stage. First we need to determine the firm's profits without first period interaction. We assume that without getting consumer inputs the high type firm can successfully serve the high type consumers only with an exogenously known probability $p_{0}$. We could, of course, assume that the firm would not be able to serve the high type consumers at all without interacting with them, but such a restrictive assumption is not necessary. It can be incorporated easily by putting $p_{0}=0$. The second stage problem faced by the high type firm is

\section{$\mathbf{P}_{3}$ :}

$$
\underset{p_{2}, \mathrm{y}_{2}}{\arg \max }\left(N^{L}+p_{0} N^{H}\right)\left(p_{2}-c_{2} y_{2}^{2}\right)
$$

subject to

$$
\begin{aligned}
& N^{L}\left(p_{1}-c_{1} y_{1}^{2}\right) \geq\left(N^{L}+p_{0} N^{H}\right)\left(p_{2}-c_{1} y_{2}^{2}\right) \\
& \left(N^{L}+p_{0} N^{H}\right)\left(p_{2}-c_{2} y_{2}^{2}\right) \geq N^{L}\left(p_{1}-c_{2} y_{1}^{2}\right) \\
& \pi^{1}\left(\theta_{1} y_{1}-p_{1}\right)+\pi^{2}\left(\theta_{1} y_{2}-p_{2}\right) \geq 0 \\
& \pi^{2}\left(\theta_{2} y_{2}-p_{2}\right) \geq 0 \\
& \mathrm{p}_{2} \geq 0, \mathrm{y}_{2} \geq 0
\end{aligned}
$$


Note that in this case the reservation utility in the individual rationality constraint of the high type consumers is zero. The second stage problem for the low type firm is.

$\mathbf{P}_{4}$ :

$$
\underset{p_{1}, \mathrm{y}_{1}}{\arg \max } N^{L}\left(p_{1}-c_{1} y_{1}^{2}\right)
$$

subject to

$$
\begin{aligned}
& N^{L}\left(p_{1}-c_{1} y_{1}^{2}\right) \geq\left(N^{L}+p_{0} N^{H}\right)\left(p_{2}-c_{1} y_{2}^{2}\right) \\
& \left(N^{L}+p_{0} N^{H}\right)\left(p_{2}-c_{2} y_{2}^{2}\right) \geq N^{L}\left(p_{1}-c_{2} y_{1}^{2}\right) \\
& \pi^{1}\left(\theta_{1} y_{1}-p_{1}\right)+\pi^{2}\left(\theta_{1} y_{2}-p_{2}\right) \geq 0 \\
& \pi^{2}\left(\theta_{2} y_{2}-p_{2}\right) \geq 0 \\
& p_{1} \geq 0, \mathrm{y}_{1} \geq 0,
\end{aligned}
$$

Solving the two simultaneously, we obtain the optimal prices and qualities when the firms do not interact with consumers in the first stage. They are summarized in proposition 2 .

Proposition 2:The optimal prices chosen by the firms in the second stage when they do not interact with consumers in the first stage are

$$
p_{1}^{*}=\frac{\theta_{1}^{2}}{2 c_{1}}, \text { and } p_{2}^{*}=\frac{\theta_{2}^{2}}{2 c_{2}}
$$

And the optimal qualities are

$$
y_{1}^{*}=\frac{\theta_{1}}{2 c_{1}}, \text { and } y_{2}^{*}=\frac{\theta_{2}}{2 c_{2}} \text {. }
$$

Proof: Same as proposition 1. 
Note that the optimal qualities are the same with and without interaction. This is because, in our model successful interaction does not improve the quality of the product in the Kaldorian sense (i.e., for all consumers). In other words, each consumer's input improves the quality of the product only in the sense of bringing it closer to his or her preferred point, but it does not improve the product for anyone else. This is pure customization and not product improvement through consumer input. Customization here means that the firm satisfies the needs of a larger number of consumers but does not have to improve the quality of the product in the Kaldorian sense to do so.

Let the possible effort levels be $e=1$ if the consumer interacts and $e=0$ if he does not. Also, let the marginal cost of effort for interacting is $c(1)=c$. Obviously, there is no cost to the consumer if he/she chooses not to interact, i.e $c(0)=0$. Let $w^{H}(e)$ be the compensation that the high type firm pays for effort $e$. Similarly, $w^{L}(e)$ is the compensation that the low-type firm pays for effort $e$.

Let us first consider the high type firm. If the high type firm has to get higher profit from interaction than without interaction then the following should be satisfied when it interacts with the high type consumer

$$
\left(N^{L}+N^{H}\right)\left[\frac{\theta_{2}^{2}}{4 c_{2}}+\frac{c(1)}{\pi^{2}}\right]-\left[\frac{\left(N^{L}+N^{H}\right)}{\pi^{2}}+N^{H}\right] w^{H}(1) \geq\left(N^{L}+p_{0} N^{H}\right) \frac{\theta_{2}^{2}}{4 c_{2}}
$$

Which gives $w^{H}(1) \leq w_{\max }^{H}(1)=\frac{\left(1-p_{0}\right)\left(N^{H}\right)\left(\theta_{2}^{2} / 4 c_{2}\right)+\left(N^{L}+N^{H}\right)\left(c / \pi^{2}\right)}{N^{H}+\left(\left(N^{L}+N^{H}\right) / \pi^{2}\right)}$

The analogous inequality when the high type firm interacts with the low type consumer is. 
$\left(N^{L}+N^{H}\right) \frac{\theta_{2}^{2}}{4 c_{2}}-\left[\frac{\left(N^{L}+N^{H}\right)}{\pi^{2}}+N^{H}\right] w^{H}(0) \geq\left(N^{L}+p_{0} N^{H}\right) \frac{\theta_{2}^{2}}{4 c_{2}}$

Which gives $w^{H}(0) \leq w_{\max }^{H}(0)=\frac{\left(1-p_{0}\right)\left(N^{H}\right)\left(\theta_{2}^{2} / 4 c_{2}\right)}{N^{H}+\left(\left(N^{L}+N^{H}\right) / \pi^{2}\right)}$

Now, for the low type firm it should be the case that it is better off not interacting than by interacting. Thus when it interacts with the high type consumer

$\frac{N^{L} \theta_{1}^{2}}{4 c_{1}} \geq N^{L}\left[\frac{\theta_{1}^{2}}{4 c_{1}}-\frac{c(1)}{\pi^{1}}\right]+\left[\frac{N^{L}}{\pi^{1}}-N^{H}\right] w^{L}(1)$

Which gives $w^{L}(1) \geq w_{\min }^{L}(1)=\frac{-\left(c N^{L} / \pi^{1}\right)}{N^{H}-\left(N^{L} / \pi^{1}\right)}$

Similarly, when it interacts with the low type consumer

$\frac{N^{L} \theta_{1}^{2}}{4 c_{1}} \geq N^{L}\left[\frac{\theta_{1}^{2}}{4 c_{1}}\right]+\left[\frac{N^{L}}{\pi^{1}}-N^{H}\right] w^{L}(0)$

Which gives $w^{L}(0) \geq w_{\min }^{L}(0)=0$

From (14) and (16), the high type firm can credibly separate (and thus signal its type) in equilibrium if it offers optimal first period compensation $w^{*}(1)$ for those consumers that choose to interact in the first stage, such that

$w_{\min }^{L}(1) \leq w^{*}(1) \leq w_{\max }^{H}(1)$.

Now, if $N^{H}-\left(N^{L} / \pi^{1}\right)>0$ then $w_{\min }^{L}(1)$ is negative. Also, we need $w^{*}(1) \geq c$ for the consumers who are in the market in the second stage to buy the high type firm's product. This follows from their participation constraint $\theta_{2} y_{2}-p_{2} \geq 0$ and constraint (9) in $\mathbf{P}_{2 .}$ From (14) $w^{*}(1) \geq c$ implies that $\left(1-p_{0}\right)\left(\frac{\theta_{2}^{2}}{4 c_{2}}\right)>c$.

From this and inequality (18) we finally have $c \leq w^{*}(1) \leq w_{\max }^{H}(1)$ 
We now turn to the equilibrium behavior of the consumers in the first stage. Let us first consider the case when consumers interact with the high type firm. The high type firm wants to design the mechanism such that, in equilibrium, low type consumers in the first stage do not interact with it while high type consumers do. The self-selection constraint for the low type consumers is

$$
(2-\underline{p}) w^{H}(0) \geq(2-\underline{p}) w^{H}(1)-\left(1+\frac{1}{\underline{k}}-\underline{p}\right) c
$$

Where the left hand side is the utility to the low type consumer if s/he does not interact with the high type firm and the right side is the utility if s/he does. Similarly, the self-selection constraint for the high type consumer is

$$
(2-\underline{p}) w^{H}(1)-\left(1+\frac{1}{\bar{k}}-\underline{p}\right) c \geq(2-\underline{p}) w^{H}(0)
$$

Combining these two inequalities we get

$$
\left(1+\frac{1}{\underline{k}}-\underline{p}\right) c \geq(2-\underline{p})\left[w^{H}(1)-w^{H}(0)\right] \geq\left(1+\frac{1}{\bar{k}}-\underline{p}\right) c
$$

Clearly, this is satisfied provided the high type consumer is sufficiently more "knowledgeable" as compared to the low type consumer. Hence our next proposition

Proposition 3: The high type firm can successfully screen consumers, encouraging only high types consumers to interact if the expertise required to provide 'useful' product information is sufficiently high.

Similarly we can treat the case of the low type firm. In that case, if $N^{H}-\left(N^{L} / \pi^{1}\right)>0$ then from (16) and (17) it is clear that the low type firm will not be able to pay positive compensation to consumers to encourage them to interact with it. Given this, neither the low type nor the high type consumer will interact with the 
firm. This follows because $\left(1+\frac{1}{\underline{k}}-\underline{p}\right) c \geq(2-\underline{p})\left[w^{L}(1)-w^{L}(0)\right]$ is trivially satisfied for any feasible compensation that the firm could pay to the low type consumers to make them interact. Hence the low types will prefer not to interact. Moreover, $\left(1+\frac{1}{\bar{k}}-\underline{p}\right) c \geq(2-\underline{p})\left[w^{L}(1)-w^{L}(0)\right]$ is trivially satisfied ensuring that the high type consumer will also choose not to interact with the low type firm.

If, on the other hand $N^{H}-\left(N^{L} / \pi^{1}\right)<0$ then it is optimal for the low type firm not to interact with the high type consumer if

$$
w^{L}(1) \leq w_{\max }^{L}(1)=\frac{\left(c N^{L} / \pi^{1}\right)}{\left(N^{L} / \pi^{1}\right)-N_{1}^{H}}
$$

Similarly, it is optimal for it not to interact with low type consumers if

$$
w^{L}(0) \leq w_{\max }^{L}(0)=0
$$

The critical values of the compensation for the high type firm remain unchanged and are given by (14) and (15) above. Finally, as we noted before we need to satisfy $w^{*}(1) \geq c$. Clearly $c<\frac{\left(c N^{L} / \pi^{1}\right)}{\left(N^{L} / \pi^{1}\right)-N^{H}}$ and for a feasible range of parameters, $w_{\max }^{L}(1)<w_{\max }^{H}(1)$. Thus, in this case the high type firm can credibly separate itself from the low type firm if $c \leq w^{*}(1) \leq w_{\max }^{L}(1)$.

From our analyses above we are led to the following proposition.

Proposition 4: There exists a Separating equilibrium with the following properties.

The high type firm interacts in equilibrium and the low type firm does not. The first stage optimal compensation $w^{*}(1)$ is given by $c \leq w^{*}(1) \leq w_{\max }^{H}(1)$. 
Therefore, in the least-cost separating equilibrium, $w^{*}(1)=c$. In other, words there is no first stage over-compensation in the least cost separating equilibrium.

The high type consumers provide their customization information while low type consumers do not.

The equilibrium prices set by the high type and low type firm in the second stage are $p_{1}^{*}=\frac{\theta_{1}^{2}}{2 c_{1}}$ and $p_{2}^{*}=\frac{\theta_{2}^{2}}{2 c_{2}}$ respectively.

The equilibrium profits for the high type and low type firm are $\left(N^{L}+N^{H}\right)\left(\frac{\theta_{2}^{2}}{4 c_{2}}\right)-N^{H} c$ and $N^{L}\left(\frac{\theta_{1}^{2}}{4 c_{1}}\right)$ respectively.

The utility of the high type consumer is $\left(1-\frac{1}{k}\right) c$.

Interestingly, the optimum prices with interaction are the same as in the nointeraction case. In the case of the low type firm it is because it does not interact in equilibrium. In the case of the high type firm it is because the compensation by the firm exactly equals consumer's cost of providing input. This means that prices of customized products are the same as those of non-customized ones. Since it is only the high type firm that can successfully customize, we only discuss the high type firm in explaining our result. Our pricing result runs counter to conventional wisdom and to statements in the trade press that consumers would be willing to pay more for customized products. These statements argue that, customized products would be priced higher than non-customized ones since they more closely match each consumer's needs. The key to understanding our result is to realize that the roles of producer and consumer in customization are not as clearly demarcated as in traditional markets. Intuitively, the high type firm can better serve consumers and 
better fulfil their needs because of its knowledge about consumers customization needs. But it is the consumers themselves who are the 'producers' of that information. In other words, the consumers themselves are responsible for producing that part of the value in the final product. Since they create that part of the value addition in the product, the firm cannot charge a higher price for it. Note that the price that the firm charges for the customized product is equal to the price of the high quality standardized product (the one that the high type consumers consume without interacting with the producer). By offering customized products the firm can sell more high quality products but not at a higher price.

Let us provide some intuition for the separating equilibrium. In equilibrium the non-experts do not interact. The experts interact and incur a cost $c$ for doing so. The interacting firm has to offer them compensation of at least $c$ to encourage them to interact. If they did not, strategic consumers would get negative utility from interacting and would prefer not to do so. This is the case because, after having sunk in the first stage cost, they would rationally expect the firm to set second stage prices so as to extract all their surplus from consuming the product. Given this strategic behavior consumers would be left with negative net utility corresponding to their first stage cost of interacting. This is related to the firm's commitment to give surplus through a low price in the second stage. Rational consumers realize that such a commitment is not credible, since, by the time the firm sets prices in the second stage, they will already have incurred the cost of providing information. In other words, such a commitment is not subgame perfect and the firm has to provide surplus in the first stage itself. Thus the low type firm has to pay consumers for information about their customization requirements, if it chooses to interact with consumers to elicit their private information. But, having done that, it cannot translate this information 
into additional sales as it fails to customize successfully. This forces it to charge higher prices for its products to recover the higher input costs if it did interact. But then the low type firm would not be able to sell and so it chooses not to interact. The high type firm also has to pay to obtain consumer's information. But since it can successfully use this customization information, it realizes higher sales. Therefore the high type firm chooses to interact. This brings into focus the strategic role of firms' compensating consumers for information. Given the reluctance of consumers to go through the effort of helping firms take the guesswork out of serving their needs, such payments could be a great inducement for them to part with private information. Moreover our results highlight the role of such payments in acting as signals for firms, which are high quality customizers. From a managerial point of view, having to pay for consumer's information need not be seen as a necessary evil. Under certain circumstances this could act as a signal of quality for a good custiomizer.

\subsection{Competition between firms}

After treating the monopoly case, we now incorporate competition between firms. Suppose there are two firms who wish to interact with consumers to provide products to them. To simplify our exposition, we assume that both firms are symmetric in every respect. As in the monopoly case above, each firm could be either a low type or a high type with probabilities $\pi^{1}$ and $\pi^{2}$ respectively. Consumers can either provide information about their customization requirements to both the firms or to only one of the firms. If they provide information to both the firms then the two firms could compete for market share in the second stage. Obviously, if consumers choose not to provide information to a firm, that firm cannot serve them fully in the second stage. Our aim is to study the interaction of the information market and the product market. 
The information market arises in the first stage as a result of the firm's competition for consumer's private information about their customization needs. The product market arises because the firms, having obtained this information, will fight for market share in stage two. Note, that the consumers' choice of whether to interact with one firm or with both firms changes only the structure of the product market. Therefore, the structure of the information market is exogenous to the consumer's decision to interact with one or both firms. The consumer takes as given the presence of two firms in the first stage, both of which wish to obtain information about their customization needs. The consumer's choice decides if the product market is a monopoly or a duopoly. If the consumer interacts with only one firm, there is competition only in the information market and the product market is a monopoly. If the consumer interacts with both firms, then there is competition both in the information market and the product market, which now becomes a duopoly. We first tackle the case where the consumer interacts with only one firm.

\section{Consumer Interacts With One Firm (Competition only in information market)}

In this case the second stage game stays the same as in the monopoly case above. Let the optimal first period compensation when there is competition only in the information market be denoted by $w_{I}^{*}(1)$. As in proposition 4 , there also exists a separating equilibrium where the high type firm interacts in equilibrium and the low type firm does not. Expert consumers provide customization information.

Competition between the firms for information results in a first stage compensation of $w_{I}^{*}(1)=w_{\max }^{H}(1)$. Thus, in this case

$$
w_{I}^{*}(1)=\frac{\left(1-p_{0}\right)\left(N^{H}\right)\left(\theta_{2}^{2} / 4 c_{2}\right)+\left(N^{L}+N^{H}\right)\left(c / \pi^{2}\right)}{N^{H}+\left(\left(N^{L}+N^{H}\right) / \pi^{2}\right)}
$$


Substituting for $w^{*}(1)$ from above, the optimal profit for the firm is

$$
\left(N^{L}+N^{H}\right)\left(\frac{\theta_{2}^{2}}{4 c_{2}}\right)-\left(1-p_{0}\right) N^{H}\left(\frac{\theta_{2}^{2}}{4 c_{2}}\right)
$$

From a comparison of (22) with (23) we see that the firm does better when there is no competition in the information market. This follows because $\left(1-p_{0}\right)\left(\frac{\theta_{2}^{2}}{4 c_{2}}\right)>c, \mathrm{a}$ condition which has to be satisfied for the high type firm to separate from the low type in equilibrium. The equilibrium utility for the high type consumer is $(2-\underline{p}) w_{I}^{*}(1)-\left(1+\frac{1}{k}-\underline{p}\right) c$ with $w_{I}^{*}(1)$ as given by (22) above. This utility is greater than $\left(1-\frac{1}{-}\right) c$ as $w_{I}^{*}(1)>c$. Thus, the consumer's utility is higher than the case where there is no competition for information. The optimal qualities provided by the high type and low type firm are the same as in the monopoly case, but the optimal price differs for the high type firm. The equilibrium prices are $p_{1}^{*}=\frac{\theta_{1}^{2}}{2 c_{1}}$ and $p_{2}^{*}=\frac{\theta_{2}^{2}}{2 c_{2}}-\frac{w_{I}^{*}(1)-c}{\pi^{2}}$ for the low type and the high type firm respectively. Thus, the high type firm charges a lower price as compared to the case when there is no interaction. The low type firm charges the same price as it does not interact in equilibrium.

It is instructive to see the reasons why the prices in the interaction case differ from those in the no-interaction case for the high type firms, unlike in the monopoly case. The high type firm has to pay to obtain consumer's information in the first stage. Now, as we already saw, in the presence of competition for that information, it has to overcompensate the consumers by paying them more than their cost of providing 
information. But, after having paid them a positive surplus in the first stage, the firm has in fact increased the consumer's incentive to renege and withhold purchase in the second stage. Hence, it has to charge lower prices in the second stage to induce such overcompensated consumers to purchase its product. Thus we see that a higher input cost for the producer in the upstream market for information cannot be translated into a higher price in the downstream product market. On the contrary it results in a lower price. This counter-intuitive result is due to the special role of the consumer in consumer-producer interaction. The same agent (that we have called consumer) plays the role of producer and price maker in the upstream market (for information) and the role of consumer and price taker in the downstream market (for products). Finally we tackle the case where firms compete both in the information market and product market.

\section{Consumer Interacts With Both Firms (Competition in product and information}

\section{market)}

If the consumer interacts with both firms, the structure of the product market in the second stage is different from that of the case discussed above. In the second stage the two firms compete for market share. We first solve the firms' second stage problem, which is now different than the two cases discussed above. The second stage problem faced by a low type firm, when it interacts in the first stage, is

P5:

$\underset{p_{1}, \mathrm{y}_{1}}{\arg \max } \pi^{1} \frac{N^{L}}{2}\left(p_{1}-c_{1} y_{1}^{2}\right)+\pi^{2} \frac{N^{L}}{2}\left(p_{1}-c_{1} y_{1}^{2}\right)$

subject to 


$$
\begin{aligned}
& \frac{N^{L}}{2}\left(p_{1}-c_{1} y_{1}^{2}\right) \geq \pi^{1}\left(\frac{N^{L}}{2}+N^{H}\right)\left(p_{2}-c_{1} y_{2}^{2}\right)+\pi^{2}\left(\frac{N^{L}+N^{H}}{2}\right)\left(p_{2}-c_{1} y_{2}^{2}\right) \\
& \pi^{1}\left(\frac{N^{L}}{2}+N^{H}\right)\left(p_{2}-c_{2} y_{2}^{2}\right)+\pi^{2}\left(\frac{N^{L}+N^{H}}{2}\right)\left(p_{2}-c_{2} y_{2}^{2}\right) \geq \frac{N^{L}}{2}\left(p_{1}-c_{2} y_{1}^{2}\right) \\
& \pi^{1}\left(\theta_{1} y_{1}-p_{1}\right)+\pi^{2}\left(\theta_{1} y_{2}-p_{2}\right) \geq 0 \\
& \pi^{2}\left(\theta_{2} y_{2}-p_{2}\right) \geq 2[w-c(e)] \\
& p_{1} \geq 0, \mathrm{y}_{1} \geq 0,
\end{aligned}
$$

The objective function to be maximized is the low type firm's expected profit and is the sum of two terms. The first term is the profit of the low type firm if the other firm is of the low type too, and this happens with probability $\pi^{1}$. In this case they serve only the low type consumers, and they split the market as the firms are symmetric. The second term in the profit function is the low type firm's profit if the other firm is of high type, which happens with probability $\pi^{2}$. Since the high type firm can also serve the low type consumers, the firms again split the market equally. The first and second constraints are the firms' incentive compatibility constraints, which ensure that the firms choose their own qualities and prices instead of mimicking the other type. The right hand side of the first constraint is the low type firm's expected profit from mimicking the high type firm. The first term on the RHS is the low type firm's profit from choosing the high type's prices and qualities if the other firm is of the low type. Since its competitor is of the low type and it mimics a high type, it sells to all the high type consumers in the market and to half of the low type consumers as the competitor can also sell to the low types. The second term corresponds to a situation in which the other firm is of the high type, and in this case the two firms equally split the entire market- both the high and low type consumers. Similarly, a high type's second stage problem, when it interacts in the first stage, is given by 
$\underset{p_{2}, \mathrm{y}_{2}}{\arg \max } \pi^{1}\left(\frac{N^{L}}{2}+N^{H}\right)\left(p_{2}-c_{2} y_{2}^{2}\right)+\pi^{2}\left(\frac{N^{L}+N^{H}}{2}\right)\left(p_{2}-c_{2} y_{2}^{2}\right)$

subject to

$$
\begin{aligned}
& \frac{N^{L}}{2}\left(p_{1}-c_{1} y_{1}^{2}\right) \geq \pi^{1}\left(\frac{N^{L}}{2}+N^{H}\right)\left(p_{2}-c_{1} y_{2}^{2}\right)+\pi^{2}\left(\frac{N^{L}+N^{H}}{2}\right)\left(p_{2}-c_{1} y_{2}^{2}\right) \\
& \pi^{1}\left(\frac{N^{L}}{2}+N^{H}\right)\left(p_{2}-c_{2} y_{2}^{2}\right)+\pi^{2}\left(\frac{N^{L}+N^{H}}{2}\right)\left(p_{2}-c_{2} y_{2}^{2}\right) \geq \frac{N^{L}}{2}\left(p_{1}-c_{2} y_{1}^{2}\right) \\
& \pi^{1}\left(\theta_{1} y_{1}-p_{1}\right)+\pi^{2}\left(\theta_{1} y_{2}-p_{2}\right) \geq 0 \\
& \pi^{2}\left(\theta_{2} y_{2}-p_{2}\right) \geq 2[w-c(e)] \\
& p_{2} \geq 0, \mathrm{y}_{2} \geq 0,
\end{aligned}
$$

Solving the two constrained maximization problems is straightforward but tedious, and we will not show it here. It is analogous to the proof of Proposition 1. It is also straightforward to establish conditions under which the separating equilibrium of the monopoly case holds - i.e., the high type firms choose to interact and the low type firms do not. Here we are concerned with the comparison of the firms' profits and consumers' utilities when there is competition only in the information market versus when there is competition in both the information and product markets. Therefore we do not visit the conditions of the separating equilibrium in detail. They are available from the authors upon request. Moreover, since the low type firm does not interact in equilibrium, we only present the more interesting case of the high type firm here. The optimal second stage price and quality of the high type firm, as functions of first stage decision variables, are $p_{2}^{*}=\frac{\theta_{2}^{2}}{2 c_{2}}+\frac{2(c(e)-w)}{\pi^{2}}$ and $y_{2}^{*}=\frac{\theta_{2}}{2 c_{2}}$

Each high type firm's profit, after substituting second stage optimal quantities, becomes 


$$
\left[\frac{N^{L}}{2}+\left(\pi^{1}+\frac{\pi^{2}}{2}\right) N^{H}\right]\left[\frac{\theta_{2}^{2}}{4 c_{2}}+\frac{2 c(e)}{\pi^{2}}\right]-\left[\frac{N^{L}}{\pi^{2}}+\left(\pi^{1}+\frac{\pi^{2}}{2}\right) \frac{2 N^{H}}{\pi^{2}}+N^{H}\right] w^{H}(1)
$$

Moreover the optimal second period price and quality of the high type firm when it does not interact is as given by proposition 2 . The profit without interaction is $\left[\frac{N^{L}}{2}+\left(\pi^{1}+\frac{\pi^{2}}{2}\right) p_{0} N^{H}\right]\left(\frac{\theta_{2}^{2}}{4 c_{2}}\right)$

For interaction to be profitable for each high type firm we need

$$
\begin{aligned}
& {\left[\frac{N^{L}}{2}+\left(\pi^{1}+\frac{\pi^{2}}{2}\right) N^{H}\right]\left[\frac{\theta_{2}^{2}}{4 c_{2}}+\frac{2 c(e)}{\pi^{2}}\right]-\left[\frac{N^{L}}{\pi^{2}}+\left(\pi^{1}+\frac{\pi^{2}}{2}\right) \frac{2 N^{H}}{\pi^{2}}+N^{H}\right] w^{H}(1) \geq} \\
& {\left[\frac{N^{L}}{2}+\left(\pi^{1}+\frac{\pi^{2}}{2}\right) p_{0} N^{H}\right]\left(\frac{\theta_{2}^{2}}{4 c_{2}}\right)}
\end{aligned}
$$

This gives $w^{H}(1) \leq \frac{\left(1-p_{0}\right)\left(\frac{\pi^{2}}{2}+\pi^{1}\right) N^{H}\left(\theta_{2}^{2} / 4 c_{2}\right)+\left[\frac{N^{L}}{2}+\left(\frac{\pi^{2}}{2}+\pi^{1}\right) N^{H}\right]\left(2 c / \pi^{2}\right)}{N^{H}+\left(2 / \pi^{2}\right)\left[\frac{N^{L}}{2}+\left(\frac{\pi^{2}}{2}+\pi^{1}\right) N^{H}\right]}$

First period competition between the firms makes each firm offer the quantity on the right above as the unique compensation. Let the equilibrium compensation, when there is competition between firms both in the information market and product market, be denoted as $w_{I P}^{*}(1)$. Thus,

$$
w_{I P}^{*}(1)=\frac{\left(1-p_{0}\right)\left(\frac{\pi^{2}}{2}+\pi^{1}\right) N^{H}\left(\theta_{2}^{2} / 4 c_{2}\right)+\left[\frac{N^{L}}{2}+\left(\frac{\pi^{2}}{2}+\pi^{1}\right) N^{H}\right]\left(2 c / \pi^{2}\right)}{N^{H}+\left(2 / \pi^{2}\right)\left[\frac{N^{L}}{2}+\left(\frac{\pi^{2}}{2}+\pi^{1}\right) N^{H}\right]}
$$

By comparing (22) and (24) one can check that the optimal compensation when firms compete only in the information market is higher than the compensation when the firms compete in both the information and product market (provided the consumer's marginal cost of providing information is sufficiently small compared to the utility they obtain when the firm successfully supplies a product incorporating that 
information). See appendix B for the exact conditions. Intuitively, the consumer's compensation for providing information is directly related to the extra profit that the firm can make from that information. If there is competition in the product market, the firm makes less profit and therefore the consumer is compensated less for his or her information. The firm's profit in equilibrium is given by

$$
\left[\frac{N^{L}}{2}+p_{0}\left(\pi^{1}+\frac{\pi^{2}}{2}\right) N^{H}\right]\left(\frac{\theta_{2}^{2}}{4 c_{2}}\right)
$$

Comparing this result with (23) above, we can see that the equilibrium profit here is less than the equilibrium profit when there is competition only in the information market. This makes sense intuitively, as the firm now has to face competition both in the information market and in the product market. But surprisingly, the high type consumer's utility in equilibrium is at an intermediate level between the monopoly case and the case when there is no competition in the product market (only in information market). Since low type consumers do not interact in equilibrium, we only discuss the high type consumers in what follows. These consumers can actually be worse off with higher competition in the second stage product market. The consumer's equilibrium utility when firms face competition in both markets is $(2-\underline{p}) 2 w_{I P}^{*}(1)-\left(1+\frac{1}{\bar{k}}-\underline{p}\right) 2 c$ with $w_{I P}^{*}(1)$ as given by (25) above. This utility is greater than $\left(1-\frac{1}{\bar{k}}\right) c$ the consumer's utility in the monopoly case (because $w_{I P}^{*}(1)$ is greater than $c$ and $\bar{k}>1$ for the high type consumers). However, it is lower than the consumer's utility when there is competition only in the information market when,

$$
(2-\underline{p}) w_{I}^{*}(1)-\left(1+\frac{1}{\bar{k}}-\underline{p}\right) c>(2-\underline{p}) 2 w_{I P}^{*}(1)-\left(1+\frac{1}{\bar{k}}-\underline{p}\right) 2 c
$$

which implies that the following condition holds 


$$
w_{I}^{*}>2 w_{I P}^{*}-\left(\frac{1+(1 / \bar{k})-\underline{p}}{2-\underline{p}}\right) c
$$

It can be easily shown (see appendix C) that the above compensation condition is satisfied if the consumer's cost of providing information is sufficiently high. Taken together appendices $\mathrm{B}$ and $\mathrm{C}$ imply that the cost of providing information be neither too high nor too low. We summarize the above discussion in the following Proposition.

Proposition 5: Suppose $c$ is sufficiently high (as given in appendix C). Then firm profits and consumer surplus are higher under the monopoly regime in the product market (with competition in the information market) than if the two firms are competing in the product market.

This result is driven by the difference in compensation between when there is competition only in the information market versus competition in both product and information markets. Intuitively, when firms compete in the product market they earn less profit in equilibrium than when they are monopolists. The only determinant of whether the product market is a monopoly or a duopoly is the number of firms which have information about the consumer's customization needs. So, if both firms have this information, it is less valuable for each firm because each firm needs to charge a lower price in the product market. Thus, the firms compensate consumers less for their customization information compared to a situation where they are monopolists in the second stage. Given the compensation condition (proposition 5), this effect leads to a lower consumer utility if there is competition in the product market. It is actually 
better, therefore, for consumers to interact with only one firm and to make this firm the monopoly supplier of their customization needs, than to interact with both firms.

\section{Discussion}

In this section we discuss some features of the model above. We have assumed that, in the second stage, the consumer can determine whether the firm has successfully customized according to his or her suggestions made in the first stage, before making the purchase. The consumer then withholds purchase if s/he determines that the firm did not customize well. In this case, the firm can use the consumer's preference information to extract consumer surplus only through its pricing in the second stage. Any downward customization of the product results in consumers not buying it. However, in cases where quality cannot be determined beforehand by the consumer, the firm could use this information for extracting consumer surplus through price discrimination, downward customization of the product or both. This would generate different equilibria from the ones we analyzed.

We also assumed that consumers' input to the firm could only improve the product for these consumers themselves. Thus, the firm is subject to consumer holdup, as it cannot sell such a tailor-made product to other consumers. In terms of Porter's (1979) five-force model, this has the effect of increasing the bargaining power of the buyer. However, if consumer's input could also improve the quality of the product in the Kaldorian sense, this would not be the case. The increase in input cost (the cost of consumer information) could then be reflected in a higher output price, which is what conventional wisdom would suggest. But in such a case it would be difficult to compare the product created as a result of consumer-producer 
interaction with a product created without it, as interaction would then produce a product with a higher quality for all consumers.

Another issue is the exact mechanism by which consumers can make firms bid for their information. Consumers after all are fragmented and it may be difficult for them to extract terms from producers. In such cases, it might be useful for them to be represented by some third-party intermediary. The trade press has already suggested the rise of so-called infomediaries which can act as clearinghouses for information about seller's products and consumer's preferences (Hagel and Singer 1999a). Infomediaries could also fulfill another role. We already noted that, when the quality of customization cannot be determined by the consumers before purchase, there is incentive for the firm to downward customize. This problem can be overcome, to the benefit of consumers, if there is a strong recommendation system by which potential consumers can learn about the firm's capabilities from its previous customers. Infomediaries can play the role of such a recommendation system.

Finally, we assumed that the firm does not face any extra costs if it has to produce a customized product (over and above the cost of producing a high quality standardized product). This is likely to be true if customization involves the incorporation of consumer preferences in the product, without increasing the Kaldorian quality in the product. Since it has been argued that, this indeed is the nature of customization, this assumption is not strong. However, if customization does entail higher costs, then the prices of customized products could be higher than standardized products. Our goal was to show that prices of customized goods would not be higher than standardized goods merely because they more closely resembled consumer's true preferences or reduce competition between firms, as has been argued in the trade press. Moreover, as manufacturing technology advances, production costs 
may not be very relevant in the pricing of customized products. Prices may then be driven more by strategic forces in the market, as we have modeled in our study.

\section{Conclusions}

In this paper we have addressed some of the issues in consumer-producer interaction in customization. We modeled a situation in which consumers provide informational input about their preferences to producers who then try to supply a product incorporating that input.

Regarding the issue of 'ownership' of consumers' information, we asked the following questions: Will producers pay for consumer information? Does such payment have strategic implications for the producers? We have shown that, in equilibrium, producers pay consumers for their information. Intuitively, they have to do this because the consumers incur an upfront cost to interact with producers. But, producers' commitment to provide surplus to consumers through a lower price for the product at a later stage, lacks credibility. Therefore, in equilibrium, consumers have to be compensated for their information. Moreover, such payment can act as a signal of high quality, which enables the 'superior customizer' to separate from a 'ghost firm' which cannot customize as well.

Regarding pricing, we ask: How do equilibrium prices of customized products compare with prices of non-customized products? Contrary to what has been suggested in the trade press, we find that prices of customized products, in equilibrium, are not higher than those of non-customized ones. When there is a monopoly supplier of consumers' customization needs, the prices charged by the firm will be exactly equal to the price it charges for similar non-customized products. 
However, the supplier of customized products charges at the high end of the established price range for similar standardized products. The key to understanding this phenomenon is to realize that the roles of consumer and producer in consumerproducer interaction are not sharply demarcated. Intuitively, the producer can better serve consumers because of value-creating information 'produced' by consumers themselves. Consumers therefore are not willing to pay a higher price for the product incorporating such information. Under duopoly, with competition for consumer's information, the equilibrium prices of customized products are actually less than prices of non-customized high-quality products. This counter intuitive result comes about because, once the firm produces a customized product, it is subject to 'holdup' by the consumer for whom the product has been produced. Moreover, competition for information raises the price that the consumer receives for this information and therefore the consumer's incentive to holdup the firm. The firm therefore has to charge a lower price to induce the consumer to purchase the product. Furthermore, such consumer power prevents the producer from transferring a higher input cost (for consumer information) into a higher output price for the customized product, contrary to what we would expect in more traditional markets.

Finally, we find surprisingly that, in the market for customized products, consumers can be better off under monopoly than under a duopoly regime. This is the case because consumers act both as price makers in the upstream information market and as price takers in the downstream product market. This dual role creates a tradeoff between the prices consumers get for their information and the price they have to pay for the product. Under simple conditions that are likely to hold, it can actually be better for the consumers to interact with only one firm and to make it a monopolist supplier of their customization requirements than to interact with both firms. 
Future work could identify the exact mechanism by which consumers can make firms bid for their information. This will entail for example a careful analysis of the role of intermediaries acting as representatives for consumers. Another fruitful avenue of investigation could be to investigate the optimal level of customization. By endogenizing the degree of customization, future work could identify the optimal level of customization that producers would like to provide. This might be driven by producers' desire to avoid being heldup which, as we saw, results in a loss of producer power. In other words, there might be a divergence of interests between consumers who want a perfectly customized product and producers who are reluctant to produce such products. This effect could drive the optimal level of customization. 


\section{Appendix A}

Proof of proposition 1: Since the principal (the producer) who proposes the contract in the second stage, has private information, we need to analyze this game as a principal-agent relationship with an informed principal. This differs from standard contract theory, which assumes that the principal does not possess any private information. Also, since the reservation utilities result from an earlier contract (from the first stage game), the situation is that of common values (see Maskin and Tirole, 1992). We follow Maskin and Tirole's solution procedure to solve the subgame starting at the second stage.

From the binding individual rationality constraint of the low type consumer we have $p_{1}=\frac{\pi^{1} \theta_{1} y_{1}+\pi^{2} \theta_{2} y_{2}-\pi^{2} p_{2}}{\pi^{1}}$

Substituting for $p_{1}$ into the objective function for $\mathbf{P}_{\mathbf{1}}$ and differentiating w.r.t $y_{1}$ to get the first order condition, gives us

$$
\begin{aligned}
& y_{1}^{*}=\frac{\theta_{1}}{2 c_{1}} . \\
& p_{1}=\frac{\pi^{2} \theta_{2} y_{2}-\pi^{2} p_{2}}{\pi^{2}}+\frac{\theta_{1}^{2}}{2 c_{1}}
\end{aligned}
$$

Starred quantities are optimal quantities. Now, from the binding individual rationality constraint for the high type consumer, we have

$$
p_{2}=\frac{\pi^{2} \theta^{2} y_{2}+c(e)-w}{\pi^{2}}
$$

Substituting for $p_{2}$ in the objective function for $\mathbf{P}_{\mathbf{2}}$ and differentiating w.r.t $y_{2}$ to get the first order condition, gives us

$$
y_{1}^{*}=\frac{\theta_{2}}{2 c_{2}},
$$


$p_{2}^{*}=\frac{\theta_{2}^{2}}{2 c_{2}}+\frac{c(e)-w}{\pi^{2}}$

Putting (3) and (4) in (2) yields

$$
p_{1}^{*}=\frac{\theta_{1}^{2}}{2 c_{1}}-\frac{c(e)-w}{\pi^{1}}
$$

\section{Appendix B}

From (22) and (24) the condition for $w_{I}^{*}(1)>w_{I P}^{*}(1)$ reduces to

$$
\frac{\left\{\left(3 \pi^{2}+2 \pi^{1}-\left(\pi^{2}\right)^{2}-2 \pi^{1} \pi^{2}\right) N^{H}-\left(\pi^{2}+2 \pi^{1}\right) N^{L}\right\} \frac{\theta_{2}^{2}\left(1-p_{0}\right)}{8 c_{2}}}{\left(\pi^{2}+2 \pi^{1}-1\right) N^{H}}>c
$$

\section{Appendix C}

Making the appropriate substitutions, the condition $w_{I}^{*}>2 w_{I P}^{*}-\left(\frac{1+(1 / \bar{k})-\underline{p}}{2-\underline{p}}\right) c$

reduces to

$$
c>\frac{\left\{\left(\pi^{2}+2 \pi^{1}-1\right)\left(N^{H}\right)^{2}+\left(1+2 \pi^{1}-\frac{1}{\pi^{2}}\right) N^{L} N^{H}\right\} \frac{\left(1-p_{0}\right) \theta_{2}^{2}}{4 c_{2}}}{\frac{\alpha N^{L}}{\pi^{2}}\left(\frac{N^{L}}{\pi^{2}}+\frac{2 N^{H}}{\pi^{2}}\right)+\left(\frac{1}{\pi^{2}}+1\right) \frac{\alpha N^{L} N^{H}}{\pi^{2}}+\left(\frac{1}{\pi^{2}}+1\right) \frac{2 \alpha\left(N^{H}\right)^{2}}{\pi^{2}}-\left(\pi^{2}+2 \pi^{1}-1\right) \frac{\left(N^{H}\right)^{2}}{\pi^{2}}}
$$




\section{References}

Anderson, David M. 1997. Agile Product Development for Mass Customization. McGraw Hill, New York

Business Week, 2000. Customizing for the Masses. March 20.

Chief Executive, 1993. Mass Customization. March.

Fournier, Susan, Susan Dobscha and David Glen Mick. 1998. Preventing the Premature Death of Relationship Marketing. Harvard Business Review 76(1), $42-44$.

Gilmore, James H. and B. Joseph Pine. 2000. Markets of One: Creating CustomerUnique Value through Mass Customization. HBS Press, Boston.

Hagel III, John and Marc Singer. 1999a. Net Worth: Shaping Markets when Customers Make the Rules. HBS Press, Boston.

Hagel III, John and Marc Singer. 1999b. Private Lives. McKinsey Quarterly 1, 6-15.

Huffman, Cynthia and Barbara E. Kahn. 1998. Variety for Sale: Mass Customization or Mass Confusion. Journal of Retailing, Vol. 74 (4), 491-513.

Iyer, Ganesh and David Soberman. 2000. Markets for Product Modification Information. Marketing Science 19(3), 203-225.

Maskin, Eric and Jean Tirole. 1992. The Principal-Agent Relationship with an Informed Principal, II: Common Values. Econometrica, Vol. 60(1),1-40.

Mussa, Michael and S. Rosen. 1978. Monopoly and Product Quality. Journal of Economic Theory. 18(2), 301-317.

Peppers, Don, Martha Rogers and Bob Dorf. 1999. Is Your Company Ready for Oneto-One Marketing? Harvard Business Review 77(1), 151-160.

Porter, Michael E. 1998. On Competition. HBS Press, Boston. 
Prahalad, C. K. and Venkatram Ramaswamy. 2000. Co-opting Customer Competence. Harvard Business Review 78(1), 79-87.

Rasmusen, Eric. 1989. Games and Information. Blackwell, Cambridge MA and Oxford UK.

Sarvary, Miklos and Philip M. Parker. 1997. Marketing Information: A Competitive Analysis. Marketing Science, Vol. 16(1). 24-38.

The Economist, 2000. Business: All Yours. April 1.

Wind, Jerry and Arvind Rangaswamy. 2000. Customerization: The Second Revolution in Mass Customization. eBRC working paper, eBRC Penn State University 